\title{
Overcoming Gender Barriers in Aircraft Maintenance: Women's Perceptions in the United States
}

\author{
Patti J. Clark \\ Embry-Riddle Aeronautical University—Worldwide \\ Jason M. Newcomer \\ United States Air Force \\ Embry-Riddle Aeronautical University-Worldwide
}

Angela M. Jones

United States Air Force

University of Maryland University College

\begin{abstract}
The Federal Aviation Administration's 2014 annual airman certificate demographics report revealed that women comprise roughly $23 \%$ of the non-pilot certificated airman in the United States; however, only $2.3 \%$ of the certified aircraft mechanic workforce are women. The problem explored in this mixed-methods concurrent triangulation study was the literature gap regarding factors that impact the demographic disparity between men and women in the aircraft maintenance technician field. The purpose of the study was to understand why most women choose not to become aircraft mechanics. A total of 431 female participants completed a 13-question survey containing 5-point Likert and openended questions to collect quantitative and qualitative data that addressed the research question. Results indicated that neither motherhood nor marriage were factors that impacted a woman's interest in a career as an aircraft maintenance technician. Furthermore, there was a relationship between a woman's perception of physical limitations as a mechanic, career appropriateness, work environment safety, social acceptance, and advancement opportunities. Finally, the qualitative analysis yielded a substantial amount of informative themes and nodes that illuminated a general lack of women's knowledge regarding the field and a perception of sexual discrimination if one were to start such a career.
\end{abstract}

\section{Introduction}

While women comprise almost half of the workforce in the United States, women continue to be underrepresented in many technical fields. In fact, despite the fact that number of women attending college has exceeded men, only about 19-21 percent of undergraduate science, technology, engineering, and math (STEM) majors are women (Ma, 2011). The significant underrepresentation of women in STEM fields is not a new problem. Jacobs (1995) highlighted the problem and noted that it was fundamentally connected to gender segregation. There are very few women in aviation and aerospace fields, and fewer still in aviation maintenance. There may be significant factors affecting 
the number of women who choose aviation maintenance careers. No aviation career field reflects the level of disparity as seen among aircraft maintenance technicians.

\section{Problem Statement}

The Federal Aviation Administration's (FAA, 2014) annual airman certificate demographics report revealed that women comprise roughly $23 \%$ - or a total of 162,284 of the nonpilot certificated airman in the United States (see Appendix A). Of those women nonpilot airmen, $87 \%$ hold certificates as flight attendants. Aircraft mechanics are the next largest population and consist of only $5 \%$ of the total female workforce - or about 7,746and comprise $2.29 \%$ of the of larger 338,844-person aircraft mechanic workforce (FAA, 2014). Several studies that explored relationships between gender and career choices attribute selection to a number of factors, to include; (a) marriage, (b) motherhood, (c) sexual discrimination, and (d) fair competition (Buser, Niederle, \& Oosterbeek, 2014; Chynoweth, 2014; Dubey \& Tiwari, 2014). The specific problem explored in this study was the gap in the literature surrounding factors that create the gross imbalance between men and women in the aircraft maintenance technician workforce.

\section{Purpose Statement}

The purpose of this mixed-methods concurrent triangulation study was to examine and explore the factors that impact career selection as it pertains to women in aircraft maintenance. This study attempted to identify some of the attitudes and influential factors that steer women away from the aircraft maintenance technician career.

\section{Literature Review}

The following review of professional and academic literature formed the foundation of the research question. To fully understand the factors and reasons that lead women to choose fields other than aircraft maintenance, we had to explore the role of women in STEM fields, women in the aviation industry, and women in aircraft maintenance. Upon completion of the foregoing, we were postured appropriately to develop and address the research question.

\section{Women in STEM}

To examine the lack of women in aviation maintenance, we should start with the lack of women in technical fields. There is a great body of evidence that indicates a disproportionate number of women in so-called science, technology, engineering and mathematics (STEM) career fields. Despite significant increases in the numbers of women in management, professional and related occupations since the 1980s, women still only represent less than $25 \%$ of those employed in fields which fall under the STEM umbrella (Bureau of Labor Statistics, 2014; Beede et al., 2011). These studies point to some common findings and statistics on the number of women in these fields, and generally remain constant, especially in the last five years. What is surprising is this finding: the number of women going into certain STEM fields including computer science and mathematics has 
actually decreased (Corbett, Hill, \& St. Rose, 2010). Even more surprising is that women are beginning to outnumber men among college-educated workers with STEM degrees in these very areas (Beede et al., 2011). Chen and Moons (2015) explored the foregoing and discovered that many women were disinterested in male-dominated fields, such as STEM fields, because they felt that they would not be socially accepted or have influence in those positions. That might explain why there is such a shortage in the aviation fields, which are also predominantly male.

\section{Women in Aviation}

From the days of Lillian Todd, the first woman to build an aircraft in 1906, to Lt. Col. Eileen Collins, the first woman Space Shuttle Commander, women have been involved in all facets of aviation (Women in Aviation International, 2013). In WWII women not only flew military aircraft but also worked in the factories building aircraft for the war effort (Texas Women's University, 2014). The iconic 'Rosie the Riveter" poster and magazine cover is a well-known portrayal of women who left the home to work in the factories during WWII. In fact, in 1943, more than 310,000 women worked in the aircraft industry and comprised more than $65 \%$ of the total workforce (Rosie the Riveter, n.d.). However, most women returned back to the home and family after the end of the war even though women had demonstrated they could perform the jobs as well as their male counterparts. The question is, did women return to aviation careers?

Goyer (2014) examined data from 1960 to 2010 to understand whether the numbers of women in aviation had significantly increased. Goyer found that the numbers of women entering aviation from 1960 to 1980 was significant but since that time, little progress has been made. In 1960 less than 1\% of women in the labor force worked in the pilot or aircraft mechanic aviation fields. By 2010, the numbers had only increased to $4.3 \%$ and $2.17 \%$ respectively (Goyer). Conversely, in 1960 women accounted for approximately 4\% of lawyers and $6 \%$ of doctors and surgeons. By 2010, women lawyers accounted for $38.3 \%$ of the workforce and $31.8 \%$ of the total number of doctors and surgeons in the U.S. (Goyer).

To examine the numbers more in depth, as of 2013 a total 205,915 women held FAA Airmen Certificates in pilot and non-pilot categories (FAA, 2014). In 2005, the FAA included flight attendants for the first time and in 2013 of the 205,915 women with FAA certificates 143,701 were flight attendants (FAA). The remaining 62,214 accounted for the entire population of women holding airmen certificates. Breaking the numbers down further, 39,621 women held pilot certificates and 22,593 were non-pilots. The largest nonpilot population is mechanics at 7,917 (FAA).

Admittedly, the numbers from the FAA include only women with actual certifications. According to the U.S. Bureau of Labor Statistics (BLS), the total labor pool for airline pilots, copilots and flight engineers is 73,030 and for aircraft maintenance technicians the number is 115,410 (2013a, 2013b). These figures represent the number of people actually working in these aviation career areas. Comparing the BLS statistics to the numbers reported by the FAA, the results are similar with women making up approximately $5.5 \%$ 
of the aircraft pilot and flight engineer workforce and $2.2 \%$ of the aircraft mechanic and service technicians (U.S. Department of Labor, Women's Bureau [DOL], 2013). The predominant aviation career area with the largest number of women continues to be the flight attendant category, at $80.9 \%$ of the labor force (DOL, 2013). At the end of over a century of aviation progress, it seems the composition of the overall aviation workforce is still predominantly male.

\section{Women in Aircraft Maintenance}

Today, several aviation-related career fields are experiencing shortages and even greater numbers of workers will be needed in the future. Experts at Boeing and Airbus forecast a labor shortage in the aviation industry and predict a need of up to 600,000 aircraft maintenance technicians by 2031 (Boeing, 2014). Currently, the average aircraft maintenance technician salary is approximately $\$ 50,000$ per year (U.S. Bureau of Labor Statistics, 2013b). In recent years heavy maintenance, also known as Maintenance, Repair and Overhaul (MRO) activities, were outsourced to foreign companies to save costs. Experts predict a return of MRO work to the U.S. in the coming years, and that need should increase the pay for aircraft maintenance technicians (Team SAI Consulting Services, 2014). The commercial aircraft or air transport segment is the largest of the MRO markets and forecasted to be $\$ 57.7$ billion in 2014 with forecasted growth to $\$ 87.8$ billion by 2024 (as cited in Holland, 2013). With a compound annual growth rate (CAGR) of $4.2 \%$, the commercial aircraft sector is one of the more healthy indicators for the future of the aviation industry. Yet, in the wake of the forecasted labor needs, market growth and fair compensation, few women still appear to enter or stay in the aircraft maintenance career field.

According to the latest figures available from the FAA, women make up just $2.5 \%$ of licensed aircraft mechanics. Arguably, the numbers for aircraft mechanics are representative of only those women who hold FAA Airframe and Powerplant (A\&P) certificates (FAA, 2014). However, in a U.S. workforce of 314,622 a total of 7,746 certificated women airmen is a low number by any measurement standard.

What actions are needed to attract more women into the aircraft maintenance career field? Is it a matter of women not understanding the work or simply being uninformed of the career field and need? Or is the aircraft maintenance career field not attractive to women, i.e. perceived as dirty work? Research has found that women choose careers that have an impact and make the world a better place (Zimovan, 2014). How do we inform women of the contributions that aircraft maintenance improvements and practices have made to the world of aviation as well as other transportation sectors? If we can find ways to answer these questions then the path to solving the issue may be clearer.

\section{Research Question}

The central research question for the study was: What factors contribute to the majority of women being disinterested in aircraft maintenance careers? Why? 
To address the research question, we used quantitative analysis to examine the factors identified in the related literature that typically serve as barriers for women entering maledominated fields. We simultaneously conducted a qualitative exploration of each factor to better understand the responses. The following factors served as the pillars for the research: (a) marriage, (b) motherhood, (c) sexual discrimination, and (d) fair competition. We assessed these factors via the following tests and supported the results with related qualitative findings.

\section{Hypotheses}

a) Marriage and maintenance career interest:

$\mathrm{H}_{0}$ : Marital status has no significant impact on a woman's interest in a career as an aircraft maintenance technician.

$\mathrm{H}_{\mathrm{a}}$ : Marital status significantly impacts a woman's interest in a career as an aircraft maintenance technician.

b) Motherhood and maintenance career interest:

$\mathrm{H}_{0}$ : Parental status has no significant impact on a woman's interest in a career as an aircraft maintenance technician.

$\mathrm{H}_{\mathrm{a}}$ : Parental status significantly impacts a woman's interest in a career as an aircraft maintenance technician.

c) Career interest, career appropriateness for women, advancement opportunity, physical limitations, and work environment safety.

$\mathrm{H}_{0}$ : There is no correlation among career interest, career appropriateness for women, advancement opportunity, physical limitations, and work environment safety.

$\mathrm{H}_{\mathrm{a}}$ : There is a correlation among career interest, career appropriateness for women, advancement opportunity, physical limitations, and work environment safety.

\section{Method and Design}

The goal of this mixed-methods concurrent triangulation study was to examine and explore the factors that impact career selection as it pertains to women in aircraft maintenance via collection of data from a 13-question survey. The chosen method was most appropriate because it afforded us the quantitative data to accept/reject hypotheses, and the qualitative data to provide depth of scholarship regarding the aforementioned tests (Creswell, 2009). Given the size of the sample and convenience of collecting all of the data at one time, the concurrent triangulation design allowed us to collect simultaneously quantitative and supporting qualitative data (Creswell).

\section{Population and Sampling}

The population consisted of adult women distributed across the U.S. for which the sample $(\mathrm{n}=431)$ was taken. Amazon's MTurk ${ }^{\mathrm{TM}}$ served as the conduit for accessing the 
population given its popular use in the U.S. and distributed and diverse user demographics. The cross-sectional study covered a three-day data collection period, during which time the active link to the survey was open and confirmation codes were rotated to avoid fraudulent responses.

\section{Validity}

To ensure valid data, it was important for us to confirm that the data collection device measured the appropriate criteria (Lameck, 2013). We guided the planning of our investigation and tested our collection procures and instrument via a pilot study-or feasibility study — using MTurk ${ }^{\mathrm{TM}}$ participants $(\mathrm{n}=53)$ from the target population; the pilot participants' Worker IDs were excluded from the full study. The pilot confirmed the effectiveness of the sampling strategy and that the $\$ 0.50$ per survey incentive was sufficient. The results of the Likert questions in the pilot provided insight on areas for improvement, such as question clarity, survey length, and balancing the participant incentive against the time it took to complete the survey. Following the five Likert questions, pilot participants were afforded a comment box to provide qualitative feedback for suggested survey improvements. We used the foregoing to improve the survey and improve validity of the findings (Dolnicar, 2013).

\section{Reliability}

Reliability is paramount to assessing the quality of the collected data (Tavakol \& Dennick, 2011). We conducted a split-half coefficient expressed as a Spearman-Brown corrected correlation to assess the reliability of the survey data. We divided the scale into two equivalent halves. While splitting the items, we accounted for sequencing of items and balance. The general guidelines for alpha values: 0.90 to 1.0 are excellent, 0.80 to 0.89 are good, 0.70 to 0.79 are acceptable, 0.60 to 0.69 are questionable, 0.50 to 0.59 are poor, and below .50 are unacceptable (George \& Mallery, 2003). The value of the split-half coefficient met acceptable reliability standards with a score of 0.698 (or 0.70 ).

\section{Results}

\section{Hypothesis A: Marriage and maintenance career interest}

Hypothesis:

$\mathrm{H}_{0}$ : Marital status has no significant impact on a woman's interest in a career as an aircraft maintenance technician.

$\mathrm{H}_{\mathrm{a}}$ : Marital status significantly impacts a woman's interest in a career as an aircraft maintenance technician.

An independent-samples $t$ test was conducted to evaluate the hypothesis that a woman's marital status impacts her interest in a career as an aircraft maintenance technician. The independent variable was the respondent's marital status and the dependent variable was the interest in aircraft maintenance as a career. The test was not significant $t(429)=-.525$, $p=.60$, therefore we accepted the null hypothesis that marital status had no significant 
impact on a woman's interest in a career as an aircraft maintenance technician. Table 1 depicts the results.

Table 1

Independent-Samples $t$ Test for Hypothesis A $(n=431)$

\begin{tabular}{|c|c|c|c|c|c|c|c|}
\hline \multirow[b]{2}{*}{ Group } & \multirow[b]{2}{*}{$t$} & \multicolumn{4}{|c|}{ Marital Status } & \multirow[b]{2}{*}{ LL } & \multirow[b]{2}{*}{ UL } \\
\hline & & $d f$ & $p$ & $M$ & $S D$ & & \\
\hline Single & -.525 & 429 & .600 & -1.48 & .812 & -.194 & .112 \\
\hline Married & -.524 & 405.8 & .601 & -1.44 & .796 & -.194 & .113 \\
\hline
\end{tabular}

\section{Hypothesis B: Motherhood and maintenance career interest}

Hypothesis:

$\mathrm{H}_{0}$ : Parental status has no significant impact on a woman's interest in a career as an aircraft maintenance technician.

$\mathrm{H}_{\mathrm{a}}$ : Parental status significantly impacts a woman's interest in a career as an aircraft maintenance technician.

An independent-samples $t$ test was conducted to evaluate the hypothesis that a woman's parental status impacts her interest in a career as an aircraft maintenance technician. The independent variable was the respondent's parental status and the dependent variable was the interest in aircraft maintenance as a career. The test was not significant $t(429)=-.439$, $p=.66$, therefore we accepted the null hypothesis that parental status had no significant impact on a woman's interest in a career as an aircraft maintenance technician. Table 2 depicts the results.

Table 2

Independent-Samples $t$ Test for Hypothesis $B(n=431)$

\begin{tabular}{|c|c|c|c|c|c|c|c|}
\hline \multirow[b]{2}{*}{ Group } & \multirow[b]{2}{*}{$t$} & \multicolumn{4}{|c|}{ Parental Status } & \multirow[b]{2}{*}{ LL } & \multirow[b]{2}{*}{ UL } \\
\hline & & $d f$ & $p$ & $M$ & $S D$ & & \\
\hline No Children & -.439 & 429 & .661 & -1.48 & .862 & -.190 & .121 \\
\hline Children & -.428 & 335 & .669 & -1.45 & .763 & -.194 & .125 \\
\hline
\end{tabular}

\section{Hypothesis C: Career interest, career appropriateness for women, advancement opportunity, physical limitations, and work environment safety}

Hypothesis:

$\mathrm{H}_{0}$ : There is no correlation among career interest, career appropriateness for women, advancement opportunity, physical limitations, and work environment safety. 
$\mathrm{H}_{\mathrm{a}}$ : There is a correlation among career interest, career appropriateness for women, advancement opportunity, physical limitations, and work environment safety.

We calculated correlation coefficients among the elements of hypothesis C. By using the Bonferroni approach to control for Type I error across the 16 correlations, we required a $p$ value of less than $.005(.05 / 10=.005)$. The correlation results presented in Table 3 identify that 6 out of 10 correlations were statistically significant. With the exception of career interest, each element had at least two significant relationships with the other five elements. If a woman felt the aircraft maintenance technician's work environment was safe, she also agreed the job was appropriate, there were advancement opportunities, that women would be socially accepted, and that women were not physically limited from performing AMT functions.

Table 3

Correlations among the Ten Elements of Hypothesis $C(n=431)$

\begin{tabular}{llllll}
\hline & $\begin{array}{l}\text { Career } \\
\text { Interest }\end{array}$ & $\begin{array}{l}\text { Appropriate } \\
\text { for Women }\end{array}$ & $\begin{array}{l}\text { Advancement } \\
\text { Opportunity }\end{array}$ & $\begin{array}{l}\text { Physical } \\
\text { Limitations }\end{array}$ & $\begin{array}{l}\text { Safe } \\
\text { Environment }\end{array}$ \\
\hline $\begin{array}{l}\text { Appropriate } \\
\text { for Women }\end{array}$ & -.022 & & & & \\
$\begin{array}{l}\text { Advancement } \\
\text { Opportunity }\end{array}$ & .085 & .121 & & & \\
$\begin{array}{l}\text { Physical } \\
\text { Limitations }\end{array}$ & .010 & $-0.429^{*}$ & -.089 & & \\
$\begin{array}{l}\text { Safe } \\
\text { Environment } \\
\text { Social }\end{array}$ & .108 & $0.227^{*}$ & $0.378^{*}$ & $-0.135^{*}$ & \\
Acceptance & .080 & .098 & $0.461^{*}$ & -.067 & $0.418^{*}$ \\
\hline * Significant at the $.003(.05 / 10=.005)$ to account for Type I error. &
\end{tabular}

\section{Women's Overall Perspectives}

To support our discussion, and ultimately our conclusions, we conducted a one-sample t-test to determine if women had a significant, overall opinion regarding career interest, career appropriateness for women, advancement opportunity, physical limitations, and work environment safety. The test value was 0 , representing an absolute neutral perspective. Using the Bonferroni method, we calculated the required $p$ value to be .008 $(.05 / 6=.008)$. Table 4 displays the 5 out of 6 factors with means that are statistically different than the absolute neutral test value of 0 . Figure 1 depicts a boxplot that shows the general rating of women for each item. 
Table 4

Significance of Means

\begin{tabular}{|c|c|c|c|c|c|c|}
\hline & \multirow[b]{2}{*}{$t$} & \multicolumn{3}{|c|}{ Test Value $=0$} & \multirow[b]{2}{*}{ LL } & \multirow[b]{2}{*}{ UL } \\
\hline & & $d f$ & $p$ & $M$ & & \\
\hline $\begin{array}{l}\text { Career } \\
\text { Interest }\end{array}$ & -37.80 & 430 & $0.00 *$ & -1.46 & -1.54 & -1.39 \\
\hline $\begin{array}{l}\text { Appropriate } \\
\text { for Women }\end{array}$ & 30.02 & 430 & $0.00 *$ & 1.30 & 1.21 & 1.38 \\
\hline $\begin{array}{l}\text { Advancement } \\
\text { Opportunity }\end{array}$ & 2.83 & 430 & $0.00 *$ & 0.13 & 0.04 & 0.22 \\
\hline $\begin{array}{l}\text { Physical } \\
\text { Limitations }\end{array}$ & -21.00 & 430 & $0.00 *$ & -1.02 & -1.11 & -0.92 \\
\hline $\begin{array}{l}\text { Safe } \\
\text { Environment }\end{array}$ & 8.85 & 430 & $0.00 *$ & 0.42 & 0.33 & 0.51 \\
\hline $\begin{array}{l}\text { Social } \\
\text { Acceptance }\end{array}$ & -1.16 & 430 & 0.25 & -0.05 & -0.14 & 0.04 \\
\hline
\end{tabular}

$*=$ Significant at the $.006(.05 / 6=.008)$ to account for Type I error.

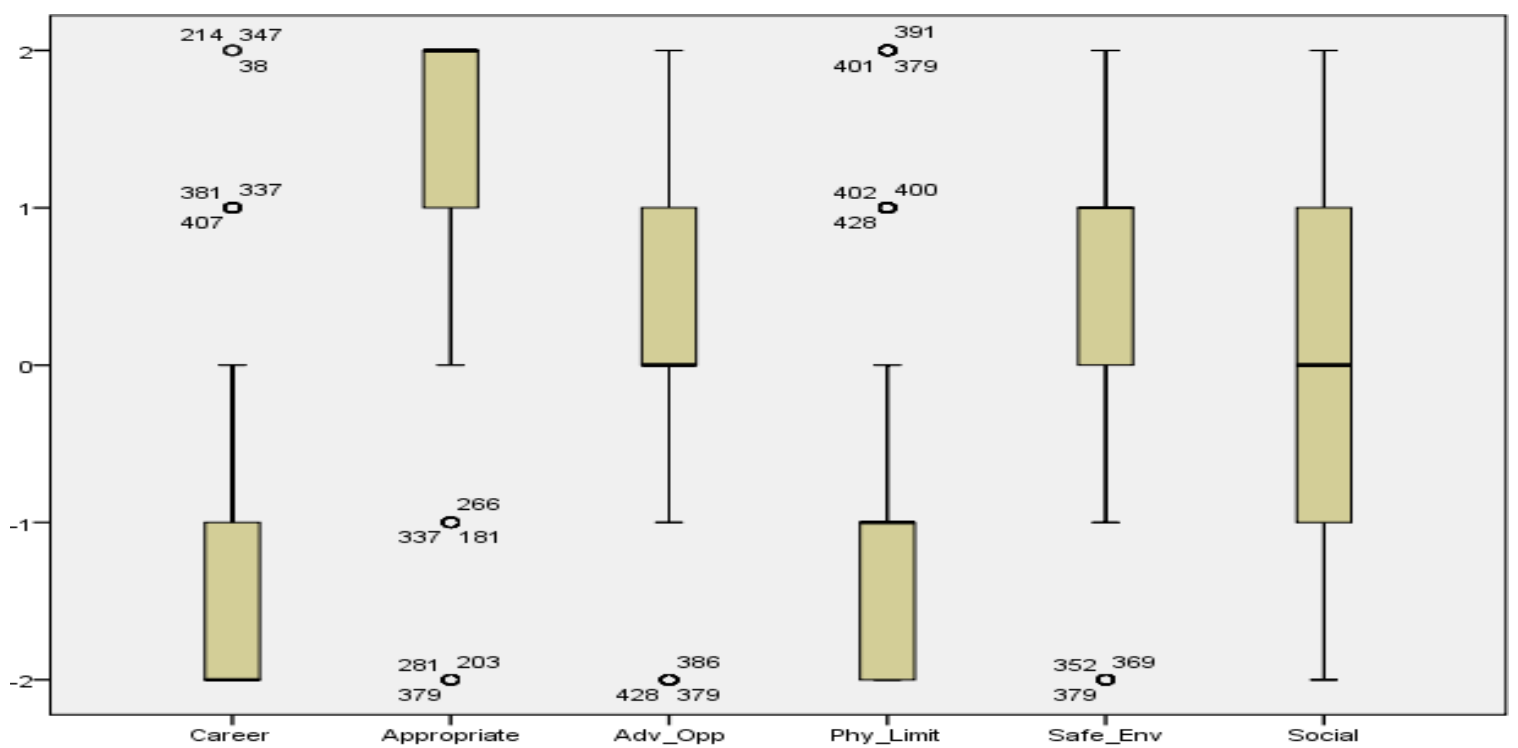

Figure 1. A boxplot representing the response distribution for each survey question.

\section{Qualitative Exploration}

The items in Figure 1 represent the overall opinions of women in the U.S. regarding aircraft maintenance. To understand the distribution of the data, each Likert question in the survey contained a mandatory short response question where participants were asked toin one or two sentences - explain why they selected their answer. Table 5 lists the coded 
themes and frequency for each theme that was relevant to addressing the research question. Themes that appear more often are believed to hold more value.

\section{Discussion}

\section{Motherhood and Marriage}

Contrary to the expectations derived from the literature, we discovered that neither parental nor marital status had a significant impact on the desire to participate in a career as an aircraft maintenance technician. Although unexpected, the implications of the findings are significant to the aircraft maintenance industry. From an operational and retention standpoint, it does not appear likely, from a woman's perspective, that the introduction of family in the form of a spouse or child will impact a current or potential aircraft maintenance technician's decision to enter or stay in the field. Because these findings conflict with literature, we can assume that they are not transferable beyond the field of aircraft maintenance.

Relationships among career interest, appropriateness for women, advancement opportunity, physical limitations, and work environment safety

We found that among our survey respondents, women who felt physical limitations were either non-existent or did not exclude a career in aircraft maintenance responded favorably to the other areas in the survey. In other words, if a woman felt she was physically able to accomplish tasks in an aircraft maintenance field, she also likely felt the field was appropriate and offered a safe working environment. If a woman felt that the field was a safe environment, she likely felt the field offered advancement opportunities and social acceptance for women. The overall consistency of the results suggest an all-in or all-out perspective of women towards the career field. Again, these inferences are significant to industry from a marketing and recruitment perspective. Marketing efforts concentrating on the actual aircraft maintenance work environment, available career paths, and any physical strength requirements will likely be well-received by women.

\section{Depth of Understanding}

The distribution of responses was expected, in most cases, based on the data provided by the FAA (2014) regarding the grossly low number of certificated women mechanics. However, the reasons explaining why the majority of women do not choose careers in aircraft maintenance remained a gap in the literature. The following sections discuss the results of the qualitative analysis in Table 5 and illuminate some of the primary reasons women chose their respective responses. 
Table 5

Qualitative Nodes and Frequencies

\begin{tabular}{|c|c|c|c|c|c|c|}
\hline & \multirow[t]{2}{*}{ Disagree } & \multirow[b]{2}{*}{$f$} & \multirow[t]{2}{*}{ Neutral } & \multirow[b]{2}{*}{$f$} & \multirow[b]{2}{*}{ Nodes } & \multirow[b]{2}{*}{$f$} \\
\hline & & & & & & \\
\hline \multirow{4}{*}{ 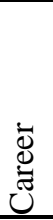 } & Not mechanically inclined & 103 & Not appealing & 18 & Sounds exciting or interesting & 40 \\
\hline & Prefer white collar work & 68 & Never considered it & 12 & Mechanically Inclined & 25 \\
\hline & Responsible for lives & 39 & Other interests & 7 & Passion for aviation & 23 \\
\hline & Other interests & 29 & Not mechanically inclined & 6 & Good pay and benefits & 18 \\
\hline \multirow{4}{*}{ 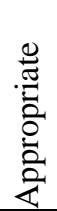 } & Appropriate for Men & 8 & Assume the career is Appropriate & 23 & Women are just as capable & 111 \\
\hline & \multirow[t]{3}{*}{ Physical Limitations for Women } & \multirow[t]{3}{*}{6} & Not Familiar with Career & 5 & Appropriate Career Choice & 133 \\
\hline & & & \multirow[t]{2}{*}{ Women Are Not Interested } & 5 & Not Gender specific & 17 \\
\hline & & & & & With Correct Skills/knowledge & 11 \\
\hline \multirow{4}{*}{ 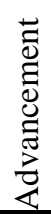 } & Discrimination/sexism & 49 & Unfamiliar with career field & 83 & Equal opportunity to advance & 82 \\
\hline & Male oriented/controlled & 18 & Not sure & 55 & Hurdles/bias/barriers & 11 \\
\hline & Women not exposed to career & 8 & Assume it is harder to advance/bias & 45 & Unfamiliar with career field & 6 \\
\hline & Unfamiliar with career field & 6 & There should be equal opportunity & 31 & Women just do not choose & 5 \\
\hline \multirow{4}{*}{ 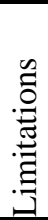 } & Women should not be limited & 129 & I do not know & 14 & Women are not as strong as men & 14 \\
\hline & Heavy lifting may not be required & 41 & Depends on the person & 7 & Women can be physically strong & 7 \\
\hline & Women can be physically strong & 37 & Women can be physically strong & 4 & Not all women are strong enough & 4 \\
\hline & Women can bridge physical gaps & 34 & Heavy lifting may not be required & 2 & Not physically suited & 2 \\
\hline & Sexual harassment/discrimination & 29 & Depends on the people/culture & 60 & Equally safe for women and men & 76 \\
\hline & Men are threatened by women & 17 & It should be safe & 47 & Predominantly male, but safe & 50 \\
\hline & Unsafe environment & 13 & Some harassment present & 12 & Generally believe it is safe & 41 \\
\hline 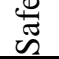 & No work environment is safe & 3 & Unsure & 5 & Men respect women as equals & 11 \\
\hline & Many men are still not accepting & 41 & Don't know & 76 & Gender discrimination is uncommon & 32 \\
\hline$\stackrel{\circlearrowright}{\Xi}$ & Not sure, but doubtful & 30 & Not sure but hopeful & 37 & Men/Women fit in equally & 25 \\
\hline$\frac{\pi}{2}$ & Women unwelcome in male field & 17 & Many men are still not accepting & 23 & No gender discrimination & 17 \\
\hline 这 & Cultural perceptions barrier & 15 & Making progress but not there & 19 & Women work just as hard as men & 14 \\
\hline
\end{tabular}


Career interest. Several reasons emerged from the data as to why women are not interested in careers as aircraft maintenance technicians. Most of the women who responded to the survey were not interested due to a perceived lack of mechanical or technical skills. Simply put, they did not feel they had the technical or mechanical ability to perform the tasks required in aircraft maintenance. Many women also felt more closely aligned with white-collar jobs than blue-collar jobs. This information might partially explain why $87 \%$ of the non-pilot certificated airmen who are women are flight attendants (FAA, 2014). For those women who were interested, it was largely due to the expectation of an exciting career, demonstrated mechanical ability, or a personal passion for the aviation industry.

Career appropriateness for women. Nearly all women who felt that the aircraft maintenance technician field was appropriate for women also felt that women were just as capable as men in the performance of all of the related tasks. Women who were neutral also assumed the foregoing but were not sure, with a small majority who just were not sure. Very few women disagreed that the career was appropriate for women and their responses were divided between responses that indicated the aircraft maintenance field was a "man's world" or that women were not physically suited for the job.

Advancement opportunities. Although more women indicated in the Likert responses that they were neutral or agree that women have equal advancement opportunities, the qualitative data provided sufficient depth to understanding the distribution of data. For example, many of the respondents who selected neutral as an answer were unsure of the existence of discrimination, but felt the bias against women would be present in the work place. It is important to note that bias or discrimination was among the top four frequencies in each coded response category. The qualitative data suggests a patent lack of knowledge regarding the advancement opportunities women have as aircraft maintenance technicians and highlights the predominant feeling of the existence of discrimination or male dominance in the career field.

Physical limitations. To understand the distribution of responses in this category it is important to note that - unlike the other questions - this question had a negative statement for agreement (i.e. "women do have physical limitations...") versus the other questions that had a positive statement for agreement (i.e. "women have equal advancement opportunities..."). Given the foregoing information, the data for this question was skewed to the right. This information translates to a majority of disagree and strongly disagree answers, as opposed to the contrary. For those women who felt there were no physical limitations, most of them felt women were no more limited than men, especially given all of the equipment available to assist with the more strenuous technician tasks. For the women who agreed that physical limitations existed, they felt men were more physically suited for the job. As with many of the categories in Table 5, the majority of neutral selections were due to a lack of knowledge surrounding the career field. 
Safe environment. The perception of physical environmental safety for women largely favored the perception that, although men dominate the field, women would be respected and generally safe in such a work environment. Of the neutral responses regarding safe working environments, most felt physical safety was dependent on the culture and people at the specific location, but overall, a safe environment should not be a concern. Discrimination and sexual harassment in the work environment were the top perceptions for those who felt the environment was unsafe for women.

Social acceptance. The qualitative views regarding social acceptance of women in an aircraft maintenance environment were primarily neutral due to a lack of knowledge regarding the work environment of aircraft maintenance technicians. Although some respondents were hopeful that an accepting culture exists (or is developing), there were more women with an opinion that women would not be socially accepted, than those who felt they would be accepted. The distribution between agreement and disagreement responses was not significantly different from zero and the overall qualitative responses reinforced the statistical finding.

\section{Assumptions, Limitations, and Delimitations}

\section{Assumptions}

The succeeding assumptions underlay the research:

- During the pilot study, all participants noted that the questions did not make them feel uncomfortable and that they answered honestly; it was reasonable to assume the same for the main study.

- The aggregate data represents the general position of the larger population.

- Study results are generalizable and researchers will be able to replicate them.

\section{Limitations}

The preceding research faced a number of internal and external challenges-most of which were generated by the geographic separation of the research team members from each other and from the participants. Skype ${ }^{\mathrm{TM}}$ served as the platform for virtual communication and there were no apparent negative impacts to the study as a result of the medium by which the team communicated. Because the survey instrument was electronically distributed and taken online via SurveyMonkey ${ }^{\mathrm{TM}}$, the physical location of the participant was irrelevant with respect to the location of each member of the research team.

Another limitation was MTurk's ${ }^{\mathrm{TM}}$ inability to target/filter workers-or participantsby gender. As a result, we expanded the questions of the survey and redeveloped it to be 
neutral to both men and women. Although the foregoing required us to collect three times as much data to reach power sample of at least 384, we were able to store the combined male and female responses $(n=1,118)$ and associated questions for future research projects.

\section{Delimitations}

This study was the first in a larger series covering the topic and not all data were presented in the study. Because of the size of the instrument, massive amount of data collected, and concern for only female responses for this particular project, we restricted the information presented. Given the foregoing, responses to survey questions not related to this study, as well as, all male respondent data were excluded.

\section{Recommendations}

It is obvious that the aviation maintenance technician career field is not well known to women in the U.S. Institutions of higher learning and industry must not only reach out to women, but also work collaboratively to educate women on the AMT career path. Internships, marketing collaborations, expansion of and commitment to women-focused aviation groups are possible ways to increase gender diversity in the AMT field. We recommend more women-focused marketing using non-traditional methods such as social media, publications that target women, and special interest groups. The fact that neither motherhood nor marriage are deterrents to women pursuing aviation maintenance technician careers means that academic institutions can use similar marketing strategies to target single and married women with and without families.

The relationships among career interest, appropriateness for women, advancement opportunity, physical limitations, and work environment safety areas of the study told us that women either believe aviation maintenance is a suitable career for women or it is not. The perception of bias indicates a need for modified diversity marketing in such a way that the industry markets not only to diverse races of men, but also women. The aforementioned suggestion brings up an interesting research question for consideration by future researchers: With the aircraft maintenance field being male-dominated at a rate of 49 to 1 , do men even consider women appropriate for the work? Why or why not? The foregoing is important, because nearly every level of work-from management to the line mechanic — will be predominantly controlled by men and their perceptions on women in their workforce will have a significant impact on women's entry.

Additional research might delineate the depth or breadth of these findings. Are certain age groups of women more informed about the aviation maintenance career than other groups? Are the bias or discrimination feelings aligned with age or ethnic groups or both? Do women outside the U.S. mirror the perspectives highlighted in this study? In cultures 
where women are just entering the workforce in large numbers, can education and communication mitigate the unawareness of the career and improve participation?

\section{Conclusions}

In the end, the study provided corroboration to the low numbers of women participating in the aviation maintenance career field in the U.S. However, we also found that while anonymity of the career field was a predominant finding, the all in or all out is the basis or key to correcting the issue. Some women in the U.S general population do believe that the aircraft maintenance technician career field is appropriate for women. The women who answered positively predominantly did so by association or knowledge of a woman involved in aviation maintenance. This finding rings true to the lack of knowledge about the career field. Now the effort needs to begin on improving communication and disseminating information at all levels to make the career more attractive to women. While this is a huge challenge, through university and industry collaboration and partnerships, we believe desired results can be achieved. 


\section{References}

Beede, D., Doms, M., Julian, T., Khan, B., Langdon, D., \& McKittrick, G. (2011). Women in STEM: A gender gap to innovation. Economics and Statistics Administration Issue Brief \#4-11. Retrieved from http://www.esa.doc.gov/reports/women-stem-gender-gap-innovation

Boeing. (2014). Boeing current market outlook . Retrieved from Boeing: http://www.boeing.com/boeing/commercial/cmo/pilot_and_technician_outlook.page?

Bureau of Labor Statistics. (2014). Labor force statistics from the current population survey. Retrieved from http://www.bls.gov/cps/cpsaat11.htm

Buser, T., Niederle, M., \& Oosterbeek, H. (2014). Gender, competitiveness, and career choices. Quarterly Journal of Economics, 129(3), 1409-1447. doi:10.1093/qje/qju009

Chen, J. M. \& Moons, W. G. (2015). They won't listen to me: Anticipated power and women's disinterest in male-dominated domains. Group Processes \& Intergroup Relations, 18(1), 116-128. doi:10.1177/1368430214550340

Chynoweth, C. (2014). The power of choice. Business Strategy Review, 25(2), 46-49. doi:10.1111/j.1467-8616.2014.01094.x

Corbett, C., Hill, C., \& St. Rose, A. (2010). Why so few? Women in science, technology, engineering, and mathematics. Washington, D.C.: AAUW.Doan, C. (2013). A Time for Renewal: The Global MRO Forecast 2013-2023. 2013 MRO Europe Conference (p. 22). London: TeamSAI, Inc.

Creswell, J. W. (2009). Research design: Qualitative, quantitative, and mixed methods approaches (3rd ed.). Thousand Oaks, CA: Sage.

Dolnicar, S. (2013). Asking good survey questions. Journal of Travel Research, 52(5), 551-574. doi:10.1177/0047287513479842

Dubey, N., \& Tiwari, V. (2014). Factors affecting career aspirations among married women. Indian Journal of Health and Wellbeing, 5(7), 59-63. Retrieved from http://www.iahrw.com/index.php/home/journal_detail/19\#list

FAA. (2014). U.S. civil airmen statistics. Retrieved from https://www.faa.gov/data_research/aviation_data_statistics/civil_airmen_statistics/20 $13 /$

George, D., \& Mallery, P. (2003). SPSS for Windows step by step: A simple guide and reference. 11.0 update $\left(4^{\text {th }}\right.$ ed.). Boston: Allyn \& Bacon. 
Goyer, M. (2014). Five decades of women pilots in the United States. How did we do? Retrieved from Institute for Women of Aviation Worldwide: http://www.womenofaviationweek.org/five-decades-of-women-pilots-in-the-unitedstates-how-did-we-do/

Holland, J. (2013). MRO global outlook 2013. Retrieved from http://www.mronetwork.com/analysis/2013/04/mro-global-outlook-2013/26

Jacobs, J. A. (1995). Gender and academic specialties: Trends among recipients of college degrees in the 1980s. Sociology of Education, 68(2), 81-98. Retrieved from http://soe.sagepub.com/

Lameck, W. U. (2013). Sampling design, validity and reliability in general social survey. International Journal of Academic Research in Business and Social Sciences, 3(7), 212-218. doi:10.6007/IJARBSS/v3-i7/27

Ma, Y. (2011). Gender differences in paths leading to a STEM baccalaureate. Social Science Quarterly, (92)5, 1169-1190. doi:10.1111/j.1540-6237.2011.00813.x

Rosie the Riveter. (n.d.). In History.com. Retrieved from http://www.history.com/topics/world-war-ii/rosie-the-riveter

Tavakol, M., \& Dennick, R. (2011). Making sense of Cronbach's alpha. International Journal of Medical Education, 2, 53-55. doi:10.5116/ijme.4dfb.8dfd

Team SAI Consulting Services. (2014, January). Global MRO market economic assessment air transport. Retrieved from AVMRO Industry Economic Data: http://arsa.org/wp-content/uploads/2014/03/ARSA-TeamSAI-EconomicReport20140319-R2.pdf

Texas Women's University. (2014). Women Air Service Pilots digital archive. Gateway to Women's History retrieved from ttp://twudigital.contentdm.oclc.org/cdm/ landingpage/collection/p214coll2

U.S Bureau of Labor Statistics. (2013a, May). Occupational employment and wages, May 2013 53-2011 airline pilots, copilots, and flight engineers. Retrieved from Occupational Employment Statistics: http://www.bls.gov/oes/current/oes532011.htm

U.S. Bureau of Labor Statistics. (2013b, May). Occupational employment and wages, May 2013 49-3011 aircraft mechanics and service technicians. Retrieved from Occupational Employment Statistics: http://data.bls.gov/oes/current/oes493011.htm\#st 
U.S. Department of Labor, Women's Bureau. (2013). Traditional and nontraditional occupations. Retrieved from http://www.dol.gov/wb/stats/nontra_traditional_ occupations.htm

Women in Aviation International. (2013). Some notable women in aviation history. Retrieved from Women in Aviation History:

http://www.wai.org/resources/history.cfm

Yingyi, M. (2011). Gender differences in the paths leading to a STEM baccalaureate. Social Sciences Quarterly, 92(5), 1169-1190. doi:10.1111/j.1540-6237.2011.00813.x

Zimovan, E. (2014, December 29). Beyond roles models for attracting women. Aviation Week \& Space Technology. 


\section{Appendix A}

FAA 2014 Nonpilot Airmen Certificate Gender Demographics

\begin{tabular}{lllllll}
\hline & $\begin{array}{l}\text { Non Pilot } \\
\text { Airmen }\end{array}$ & $\%$ & $\begin{array}{l}\text { Ground } \\
\text { Instructor }\end{array}$ & $\%$ & $\begin{array}{l}\text { Flight } \\
\text { Engineer }\end{array}$ & $\%$ \\
\hline Women & 162,284 & $100.00 \%$ & 5,568 & $3.43 \%$ & 1,685 & $1.04 \%$ \\
Men & 544,871 & $100.00 \%$ & 66,925 & $12.28 \%$ & 43,632 & $8.01 \%$ \\
Total & 707,155 & $100.00 \%$ & 72,493 & $10.25 \%$ & 45,317 & $6.41 \%$ \\
Women \% & $22.95 \%$ & & $7.68 \%$ & & $3.72 \%$ & \\
Men \% & $77.05 \%$ & & $92.32 \%$ & & $96.28 \%$ & \\
\hline
\end{tabular}

\begin{tabular}{lllllll}
\hline & Dispatcher & $\%$ & $\begin{array}{l}\text { Flight } \\
\text { Navigator }\end{array}$ & $\%$ & $\begin{array}{l}\text { Flight } \\
\text { Attendant }\end{array}$ & $\%$ \\
\hline Women & 3,480 & $2.14 \%$ & 1 & $0.00 \%$ & 140,870 & $86.80 \%$ \\
Men & 18,921 & $3.47 \%$ & 125 & $0.02 \%$ & 38,661 & $7.10 \%$ \\
Total & 22,401 & $3.17 \%$ & 126 & $0.02 \%$ & 179,531 & $25.39 \%$ \\
Women \% & $15.54 \%$ & & $0.79 \%$ & & $78.47 \%$ & \\
Men \% & $84.46 \%$ & & $99.21 \%$ & & $21.53 \%$ & \\
\hline
\end{tabular}

\begin{tabular}{lllllll}
\hline & Mechanic & $\%$ & Repairmen & $\%$ & $\begin{array}{l}\text { Parachute } \\
\text { Rigger }\end{array}$ & $\%$ \\
\hline Women & 7,746 & $4.77 \%$ & 2,285 & $1.41 \%$ & 649 & $0.40 \%$ \\
Men & 331,098 & $60.77 \%$ & 37,667 & $6.91 \%$ & 7,842 & $1.44 \%$ \\
Total & 338,844 & $47.92 \%$ & 39,952 & $5.65 \%$ & 8,491 & $1.20 \%$ \\
Women \% & $2.29 \%$ & & $5.72 \%$ & & $7.64 \%$ & \\
Men \% & $97.71 \%$ & & $94.28 \%$ & & $92.36 \%$ & \\
\hline
\end{tabular}

